\section{PUBLICATION AND CLASSIFICATION OF SCIENTIFIC KNOWLEDGE}

$\mathrm{T}$ HE direct importance to the research worker of an efficient scientific information service led the Cambridge Branch of the Association of Scientific Workers to hold a conference on October 25 to discuss various schemes that have been proposed. Although the subject had been discussed previously by professional abstractors and librarians, this was the first conference of 'users' of scientific information.

The chairman, Sir Lawrence Bragg, outlined the two main aspects of the problem: $(a)$ how are scientific workers to get to know of the work that interests them, and $(b)$ having learned of it, how can they get a copy of the actual publication. The first is by far the more difficult. As regards the second, the personal contact provided by correspondence is invaluable, and any centralizing scheme must avoid destroying this. of the suggested agency buying the copyright and a large number of reprints. Dr. E. Orowan and Prof. Hutton quoted a number of societies, mainly in the metallurgical and engineering fields, which are, in fact, partially operating the proposed scheme, as they treat the paper as the unit and later assemble them into Transactions.

Whether reprinting is the most economical method of reproduction was doubted by Mrs. Lucia Moholy, and she gave figures to support the use of microfilming, particularly when the demand could not be forecast. Dr. D. P. Riley praised the microfilm service run in conjunction with abstracts published by the Centre National de la Recherche Scientifique in Paris, and said that the French Thomson-Houston microfilm-viewer is very good. In discussion, the need for an efficient and cheap British microfilm. viewer (costing about £30) was underlined.

The different needs of the biological and physical sciences were referred to by several speakers. The abstracting service of the Imperial Bureau of Plant Breeding and Genetics was described by Mr. R. H.

\begin{tabular}{|c|c|c|c|c|c|}
\hline & $\begin{array}{c}\text { Books } \\
>50,000 \text { words }\end{array}$ & $\begin{array}{c}\text { PAMPHLETS } \\
10,000-500,000 \text { words }\end{array}$ & $\begin{array}{l}\text { PAPERS } \\
5,000-100,000 \text { words }\end{array}$ & $\begin{array}{l}\text { IETTERS or NoTES } \\
100-5,000 \text { words }\end{array}$ & $\begin{array}{c}\text { ABSTRACTS or TITLES } \\
<100 \text { words }\end{array}$ \\
\hline EPHEMERAL & & $\begin{array}{l}\text { Research } \\
\text { programmes }\end{array}$ & Lectures & $\begin{array}{l}\text { Letter on work in } \\
\text { progress }\end{array}$ & $\begin{array}{l}\text { Title of research } \\
\text { project }\end{array}$ \\
\hline OPERATIVE & & $\begin{array}{l}\text { Theses } \\
\text { (full experimental } \\
\text { detail and mathe- } \\
\text { matical argument) }\end{array}$ & $\underset{\substack{\text { The scientific } \\
\text { paper }}}{* \dagger}$ & $\begin{array}{l}\text { Note or informative } \\
\text { abstract }\end{array}$ & Indicative abstract \\
\hline COLLECTIVE & & Monographs & $\begin{array}{l}\text { Report } \\
\text { (e.g., annual) on } \\
\text { progress of a sub- } \\
\text { ject }\end{array}$ & $\begin{array}{l}\text { Book reviews and } \\
\text { critical articles }\end{array}$ & Bibliographies \\
\hline DEFINITE & Treatises & & Handbooks & $\begin{array}{l}\text { Data tables } \\
\text { (fauna - flora, } \\
\text { maps, etc.) }\end{array}$ & General indexes \\
\hline UTILITARIAN & $\begin{array}{l}\text { Text-books. Yopu- } \\
\text { lar seience books }\end{array}$ & $\begin{array}{l}\text { Practical } \\
\text { monographs }\end{array}$ & Technical articles & Technical notes & \\
\hline
\end{tabular}

Note.-The four essential units are outlined with heavier rules.

* To be received automatically. † To be received on request through agency. § Central responsibility for preparation.

Prof. J. D. Bernal divided scientific information into 'operative units' according to their length and function (see table). Thus the scientific 'paper' is the operative unit, not the journal. Abstracts should be of two kinds, 'indicative' and 'informative'. 'The former merely guides you to the paper while the latter should be full enough to be adequate for 'background' reading. By the term 'thesis', he means the fullest possible account of a piece of research, not necessarily a dissertation for a doctorate. He proposed a single subscription to a national distributing agency which would entitle one to receive automatically, say, 1,000 papers a year plus abstracts of a given field or fields. Further papers or theses could be obtained on request.

Those present at the conference agreed generally with this scheme, provided that the scientific journals continued also to be available in bound series in libraries. Prof. R. S. Hutton pointed out the present and future financial difficulties of the societies in publishing their journals, and suggested that a proper financial arrangement with such a national distributing agency might be decisive in obtaining their agreement to the scheme. Mr. J. W. S. Pringle emphasized that editorial responsibility must rest with the societies, and that it is really a question
Richens, while Prof. H. Jeffreys dealt with the position in astronomy, meteorology and geophysics. It was agreed that abstracting should always be done in one of the common European languages. Some interesting suggestions were made with reference to the classification and indexing of scientific papers, and the need for a fundamental theory of classification was made obvious. Most speakers favoured, as an immediate measure, the extension of the Universal Decimal Classification to meet the requirements of new branches of science such as nuclear physics. Mr. J. B. Hasted suggested that the cross-referencing difficulty might be overcome by using a matrix system. Dr. S. Lilley objected to the use of the decimal system, as classification on a binary scale is much more efficient and flexible. The logic of classification is better on a dual system and is ideal for use with machines. His own simple knitting. needle and punched-card system gives the possibility of $10^{33}$ classes on one card.

An editor's opinion was given by Dr. R. C. Evans. $\mathrm{He}$ compared American and British practice; he is convinced that many of the reasons for delays in publication lie in the form in which papers are submitted. The increased speed of communications should logically lead to the creation of international 
journals such as the old Zeitschrift für Kristallographie and the new Acta Crystallographica.

Some indication of the need for rationalization was provided by figures given by Prof. Hutton. The number of worthwhile scientific periodicals is 15,000 , and the number of original papers in these journals is about 750,000 per year. Of these, 1 in 3 are abstracted; but it should be noted that chemistry accounts for a great number as it is the most thoroughly abstracted branch of science.

\section{INTERPRETATION OF HIGH COERCIVITY IN FERROMAGNETIC MATERIALS}

\author{
By Prof. E. C. STONER, F.R.S., \\ AND \\ E. P. WOHLFARTH \\ Physics Department, University of Leeds
}

$I^{\mathrm{N}}$ the generally accepted theory of the ordinary magnetization curves of ferromagnetics, due to Becker, Kersten and many others, and fully described by Becker and Döring ${ }^{1}$, coercivity is related to the amplitude of internal stress variations through their effect on domain boundary movement. Although there can be little doubt as to the correctness of the basic ideas, or to their wide applicability, the treatment cannot account for coercivities of 500 oersted, and more, which are obtained in modern permanent magnet materials, without arbitrary and improbable assumptions about the magnitude and character of the internal stress variations. It occurred to one of us some years ago that for those alloys of the dispersion-hardening type for which the higher coercivities are found, an entirely different type of explanation might be possible, and some preliminary calculations gave promising results. This line of inquiry was interrupted by the War, and no more than vague references to it have been published ${ }^{2}$, though it has been discussed verbally and in correspondence with others interested. A systematic attack on the problem was resumed at the beginning of 1946 , and a full account of the work has now been prepared. In view of the inevitable delays in publication a brief account may be appropriate here. It may be stated quite frankly that the immediate stimulus to this communication has been two short and admirable papers by $\mathrm{Néel}^{3}$, which have just appeared, and which show that he has been thinking along similar lines with particular reference to powder magnets.

The central idea is that in many ferromagnetic materials there may occur 'particles' (this term including both actual powder grains and atomic segregates or 'islands' in alloys), distinct in magnetic character from the general matrix, and less than the critical size, depending on shape, for which domain boundary formation is energetically possible. For particles in the form of ellipsoids of revolution, a reasonably precise expression for the lower limit to this critical size is obtained, involving the saturation intensity, $I_{0}$, and the Curie temperature of the material of the particle and the smaller demagnetization factor. For spherical particles, the lower limit to the critical diameter is found to be $0.8 \times$ $10^{-6}$ for iron, and $3 \cdot 1 \times 10^{-8}$ for nickel, the number of atoms in the volume being about $1.5 \times 10^{5}$ and $1.2 \times 10^{7}$ respectively. For prolate spheroids of dimensional ratio 10 , the diameters are some four times as great, and the number of atoms $1 \cdot 1 \times 10^{9}$ and $8.1 \times 10^{10}$. In such single-domain particles, change of magnetization can take place only by rotation of the magnetization vector, $I_{0}$, which remains constant in magnitude and uni-directional throughout the particle. As the field changes continuously, the resolved magnetization in the field direction may change discontinuously at critical values of the field. The character of the magnetization curve depends on the degree of magnetic anisotropy of the particle, and on the orientation of the 'easy axes' with respect to the field. The magnetic anisotropy may be due to anisotropy of shape (the energy depending on direction owing to the directional dependence of the demagnetizing field), magnetocrystalline anisotropy or strain anisotropy.

A detailed quantitative treatment has been developed of the effect of shape anisotropy when the particles are in the form of ellipsoids of revolution, and a less detailed treatment for the general ellipsoidal form, of which the prolate and oblate spheroid are limiting cases. In dealing with ellipsoids of revolution it is convenient to use a non-dimensional parameter $h$, defined by $h=H /\left|\left(N_{a}-N_{b}\right)\right| I_{0}$, where $N_{a}$ and $N_{b}$ are the demagnetization coefficients along the polar and equatorial axes. The variation with $h$ of the ratio $I_{H} / I_{0}$, where $I_{H}$ is the resolved value of $I_{0}$ in the positive field direction, has been determined, by accurate numerical solution of the equilibrium equations, for a series of angles, $\theta$, ranging from $0^{\circ}$ to $90^{\circ}$, of the orientation of the polar axis with respect to the field, and also for random orientation. The magnetization curves for random orientation are shown in the accompanying figure, where the full curves refer to prolate spheroids, the broken curves to oblate spheroids.

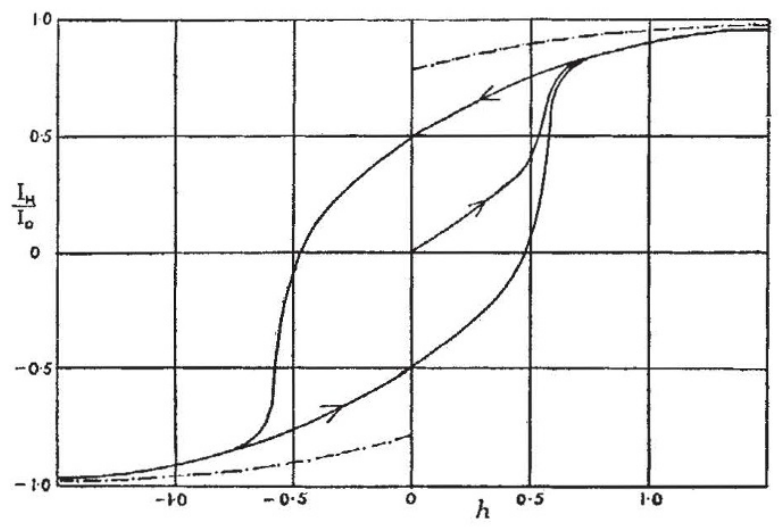

For the special limiting case of the oblate spheroid, there is no hysteresis (this applies to all orientations), though there is a discontinuous change in the magnetization as tho field passes through zero. For the prolate spheroid, exact expressions are obtained for the critical field, $h_{0}$, at which the discontinuous change occurs, and for various related quantities, as functions of the orientation angle, $\theta$. As $\theta$ varies from $0^{\circ}$ to $90^{\circ}$, the cyclic magnetization curves change from a rectangular form, with $\left|h_{0}\right|=1$, to a linear non-hysteretic form, with an interesting sequence of intermediate forms. The lowest value of $\left|h_{0}\right|$ is $\frac{1}{2}$, occurring for $\theta=45^{\circ}$.

All the numerical results are applicable when the anisotropy is due to longitudinal stress, when $h$ and $H$ 